\title{
Tumour heterogeneity of DNA cell cycle variables in breast cancer measured by flow cytometry
}

\author{
E Bergers, P J van Diest, J P A Baak
}

\begin{abstract}
Aim/background-Conflicting results have been reported concerning the prognostic value of DNA flow cytometric variables (DNA ploidy, DNA index, \%S phase fraction) in breast cancer. Selection bias and differences in treatment may have contributed to these conflicting prognostic results. Differences in tissue processing, the number of nuclei measured, DNA histogram/cell cycle analysis, and intratumour heterogeneity may also have played a role. The aim of the present study was to assess intra-tumour heterogeneity of DNA flow cytometric variables in breast cancer.

Methods-Fresh frozen specimens $(\mathbf{n}=$ 274) $(0.3 \times 0.3 \times 0.3 \mathrm{~cm})$ of 17 breast cancers and 167 slices, $50 \mu \mathrm{m}$ thick, of 58 paraffin wax embedded blocks of 21 breast cancers were studied. All samples were prepared individually for DNA flow cytometry. DNA histograms were interpreted by semi-automated cell cycle analysis (MultiCycle) by two observers to avoid biased interpretation. An artificial averaged DNA histogram of each case was composed to simulate a sample prepared from whole tumour tissue.
\end{abstract}

Results-With regard to DNA ploidy, classified as diploid or aneuploid, the fresh frozen and paraffin wax embedded breast cancers showed intra-tumour heterogeneity in $53 \%$ and $38 \%$ of cases, respectively. For fresh frozen and paraffin wax embedded material, respectively, six samples had to be measured to detect the highest DNA ploidy class in $71 \%$ and $86 \%$ of cases. Averaged DNA histograms showed a loss of DNA aneuploidy in $36 \%$ and $6 \%$ of fresh frozen and paraffin wax embedded samples, respectively. High intra-tumour heterogeneity (wide ranges) was found for the $\% S$ phase fraction. Average \%S phase fraction and average aneuploid \%S phase fraction had the widest ranges at $9.5-31.6 \%$ and $0.0-62.7 \%$, respectively. There was no correlation between the number of stemlines and intra-tumour \%S phase variability on the one hand and tumour size and grade on the other.

Conclusion-High intra-tumour heterogeneity for breast cancer was found for DNA ploidy, the DNA index and \%S phase fraction as measured by flow cytometry, which may explain the conflicting prognostic results reported in the literature. To detect aneuploid cells, six samples may have to be prepared and measured separately. Measurement of these variables may be more reliable in paraffin wax sections because the thick slices provide a more representative sample. Prospective studies are required to determine whether the highest $\% S$ phase fraction value or the average value is more useful in the clinical context.

(F Clin Pathol 1996;49:931-937)

Keywords: Breast cancer, intra-tumour heterogeneity, cell cycle analysis.

Many studies have evaluated the prognostic value of DNA flow cytometry in breast cancer. DNA ploidy, the DNA index and the percentage of cells in $S$ phase (\%S phase fraction) were reported to provide prognostically important information by many authors. ${ }^{1-11}$ Others, however, failed to show any prognostic value for these variables. ${ }^{12-16}$ Selection bias, the size of the patient cohorts studied and differences in treatment may have contributed to these conflicting prognostic results. Differences in tissue processing, the number of nuclei measured, DNA histogram/cell cycle analysis, and intratumour heterogeneity may also have played a role.

The aim of the present study was to assess intra-tumour heterogeneity of DNA flow cytometric variables (DNA ploidy, DNA index and $\% S$ phase fraction) in breast cancer, keeping all other variables constant. A tried and tested protocol incorporating the MultiCycle computer program was used for cell cycle analysis. ${ }^{171}$

\section{Methods}

Tumour size was measured in fresh resection specimens (table 1). Histological grade was assessed in routine haematoxylin and eosin stained sections, according to the modified Bloom and Richardson system as recommended by the Nottingham group. ${ }^{19}$

FRESH FROZEN MATERIAL

After harvesting sufficient tumour for routine diagnostic procedures in 17 cases of histologically confirmed invasive breast cancer, remaining tumour tissue was cut into pieces measuring $0.3 \times 0.3 \times 0.3 \mathrm{~cm}$ and snap frozen in liquid nitrogen pending flow cytometry. Depending on the size of the tumour, four to 40 pieces (274 in total) were obtained. Each piece was dissected into smaller pieces using the Vindelov procedure ${ }^{20}$ in citrate buffer containing 
Table 1. Tumour size and grade

\begin{tabular}{|c|c|c|c|c|}
\hline \multirow[t]{2}{*}{ Tumour } & \multicolumn{2}{|c|}{ Fresh frozen samples } & \multicolumn{2}{|c|}{$\begin{array}{l}\text { Paraffin wax embedded } \\
\text { samples }\end{array}$} \\
\hline & Size $(\mathrm{cm})$ & Grade & Size $(\mathrm{cm})$ & Grade \\
\hline 1 & 1.0 & 2 & 3.5 & 1 \\
\hline 2 & 1.8 & 2 & 3.5 & 2 \\
\hline 3 & 2.1 & 2 & 5.0 & 2 \\
\hline 4 & 1.2 & 1 & 1.3 & 3 \\
\hline 5 & 3.5 & 1 & 1.5 & 2 \\
\hline 6 & 2.1 & 1 & 1.0 & 1 \\
\hline 7 & 4.0 & 2 & 5.0 & 1 \\
\hline 8 & 4.0 & 2 & 3.0 & 2 \\
\hline 9 & 2.0 & 1 & 4.0 & 2 \\
\hline 10 & 6.0 & 3 & 2.9 & 1 \\
\hline 11 & 3.0 & 1 & 1.5 & 1 \\
\hline 12 & 3.5 & 3 & 7.5 & 3 \\
\hline 13 & 6.0 & 2 & 3.0 & 2 \\
\hline 14 & 5.0 & 1 & 2.1 & 3 \\
\hline 15 & 3.0 & 3 & 2.0 & 1 \\
\hline 16 & 4.0 & 2 & 1.0 & 2 \\
\hline 17 & 5.0 & 2 & 1.9 & 2 \\
\hline 18 & & & 3.0 & 3 \\
\hline 19 & & & 3.0 & 3 \\
\hline 20 & & & 2.5 & 2 \\
\hline 21 & & & 3.0 & 1 \\
\hline
\end{tabular}

$85.5 \mathrm{~g}(250 \mathrm{mM})$ sucrose (BDH Chemicals Ltd, Poole, Dorset, UK), 11.76 g (40 mM) trisodium citrate (Merck, Darmstadt, Germany), $50 \mathrm{ml}$ dimethylsulphoxide (DMSO) (Merck Inc., Rahway, New Jersey, USA) in $1000 \mathrm{ml}$ distilled water. After centrifuging for 10 minutes at $3000 \mathrm{rpm}$, the supernatant was removed and $900 \mu \mathrm{l}$ trypsin $(15 \mathrm{mg}$ in $500 \mathrm{ml}$

Table 2 Intra-tumour heterogeneity with regard to DNA ploidy

\begin{tabular}{|c|c|c|c|c|c|c|}
\hline \multirow[t]{2}{*}{ Tumour } & \multicolumn{3}{|c|}{ Fresh frozen samples } & \multicolumn{3}{|c|}{ Paraffin wax embedded samples } \\
\hline & $n$ (samples) & Diploid & Aneuploid & $n$ (samples) & Diploid & Aneuploid \\
\hline 1 & 4 & & 4 & 3 & & 3 \\
\hline 2 & 6 & & 6 & 4 & & 4 \\
\hline 3 & 6 & & 6 & 6 & 2 & 4 \\
\hline 4 & 8 & & 8 & 6 & & 6 \\
\hline 5 & 8 & 4 & 4 & 6 & & 6 \\
\hline 6 & 9 & 5 & 4 & 6 & 2 & 4 \\
\hline 7 & 11 & 6 & 5 & 6 & 3 & 3 \\
\hline 8 & 12 & 11 & 1 & 6 & 6 & \\
\hline 9 & 13 & 9 & 4 & 6 & 5 & 1 \\
\hline 10 & 14 & & 14 & 8 & & 8 \\
\hline 11 & 14 & 14 & & 8 & 8 & \\
\hline 12 & 16 & & 16 & 9 & & 9 \\
\hline 13 & 21 & 16 & 5 & 9 & & 9 \\
\hline 14 & 29 & 18 & 11 & 9 & & 9 \\
\hline 15 & 30 & 30 & & 9 & 1 & 8 \\
\hline 16 & 34 & 11 & 23 & 9 & 9 & \\
\hline 17 & 40 & 37 & 3 & 10 & & 10 \\
\hline 18 & & & & 11 & 8 & 3 \\
\hline 19 & & & & 12 & 7 & 5 \\
\hline 20 & & & & 12 & & 12 \\
\hline 21 & & & & 12 & 10 & 2 \\
\hline
\end{tabular}

Table 3 Number of tumour samples required to detect the highest DNA ploidy class

\begin{tabular}{|c|c|c|}
\hline \multirow{2}{*}{$\begin{array}{l}\text { Number of samples taken } \\
\text { per tumour }\end{array}$} & \multicolumn{2}{|c|}{ Number (\%) of tumours with the highest ploidy class } \\
\hline & $\begin{array}{l}\text { Fresh frozen samples } \\
(n=17)\end{array}$ & $\begin{array}{l}\text { Paraffin wax embedded samples } \\
(n=21)\end{array}$ \\
\hline $\begin{array}{l}1 \\
2 \\
3 \\
4 \\
5 \\
6 \\
7 \\
8 \\
9 \\
10 \\
11 \\
12 \\
13 \text { to } 32 \\
33\end{array}$ & $\begin{array}{c}8(47 \%) \\
8(47 \%) \\
8(47 \%) \\
8(47 \%) \\
10(59 \%) \\
12(71 \%) \\
12(71 \%) \\
12(71 \%) \\
14(82 \%) \\
14(82 \%) \\
14(82 \%) \\
15(88 \%) \\
16(94 \%) \\
17(100 \%)\end{array}$ & $\begin{array}{l}13(62 \%) \\
14(67 \%) \\
16(76 \%) \\
17(81 \%) \\
17(81 \%) \\
18(86 \%) \\
19(90 \%) \\
20(95 \%) \\
20(95 \%) \\
20(95 \%) \\
21(100 \%)\end{array}$ \\
\hline
\end{tabular}

stock solution, which contained $2000 \mathrm{mg}(3.4$ $\mathrm{mM})$ trisodium citrate, $2 \mathrm{ml}(0.1 \% \mathrm{v} / \mathrm{v})$ Nonidet P40 (Shell, Carrington, UK), 1044 mg (1.5 $\mathrm{mM}$ ) spermine tetrahydrochloride (S2876 Sigma, St Louis, Missouri, USA), $121 \mathrm{mg}$ (0.5 mM) Tris-(hydroxymethyl)-aminomethaan (T1378; Sigma) in $2000 \mathrm{ml}$ distilled water, $\mathrm{pH}$ 7.6) was added to the pellet and left for 10 minutes at room temperature. Then, $750 \mu \mathrm{l}$ trypsin inhibitor $(250 \mathrm{mg}$ trypsin inhibitor (T9253; Sigma), $50 \mathrm{mg}$ Ribonuclease A (T4875; Sigma) in $500 \mathrm{ml}$ stock solution) was added and left for 10 minutes at room temperature. After filtering the suspension, $750 \mu \mathrm{l}$ diamidino-phenyl-indoledihydro-chloride (DAPI; Partec, Münster, Germany) and spermine was added and kept in the dark for at least 15 minutes. The DAPI solution contained 200 $\mu \mathrm{g}$ DAPI per $\mathrm{ml}$ Tris solution, which contained $12.14 \mathrm{~g}$ Tris, $5.84 \mathrm{~g} \mathrm{NaCl}$ in $500 \mathrm{ml}$ distilled water, $6.9 \mathrm{ml} 37 \% \mathrm{HCl}$ in $800 \mathrm{ml}$ distilled water; $\mathrm{pH}$ 7.6. Ten millilitres of this solution were added to $500 \mathrm{ml}$ stock solution, which contained 580 mg spermine tetrahydrochloride.

PARAFFIN WAX EMBEDDED MATERIAL

Paraffin wax embedded tumour tissue from 21 patients with invasive breast cancer was studied. Based on control haematoxylin and eosin stained slides, those paraffin wax blocks containing invasive tumour were selected (one to four blocks; 56 in total). An average of three $50 \mu \mathrm{m}$ slices was cut from each wax block and prepared individually for flow cytometry, as described by Hedley et al. ${ }^{21}$ This procedure permitted the evaluation of intra-block heterogeneity. Briefly, paraffin wax slices were dewaxed in xylene for 10 minutes, rehydrated in ethanol and washed in phosphate buffered saline (PBS). The rehydrated sections were treated enzymatically with $3 \mathrm{ml}$ pronase $(0.5$ $\mathrm{g} / 100 \mathrm{ml} \mathrm{PBS}$ ) for 45 minutes at $37^{\circ} \mathrm{C}$. The suspension was then filtered through $50 \mu \mathrm{m}$ gauze and stained with $1 \mathrm{ml}$ DAPI, as described earlier for the fresh frozen material.

\section{FLOW CYTOMETRY}

All fresh frozen and paraffin wax embedded tissue samples from the same tumour were processed in the same batch and the cell suspensions were measured at the same time on the same day using a Partec PAS II flow cytometer (Partec, Münster, Germany). At least 50000 events were measured for each sample. Trout erythrocytes were used to calibrate the flow cytometer. The resulting DNA histograms were exported in ASCII format for analysis by the MultiCycle program (Phoenix Flow Systems, San Diego, California, USA). For each case, an artificial averaged DNA histogram was composed by summing all DNA histograms for that case and dividing by the number of samples (separately for fresh and paraffin wax embedded material). This was done in order to evaluate whether analysis of a homogenised cell suspension derived from different samples contains all of the stemlines present in individually prepared samples. 

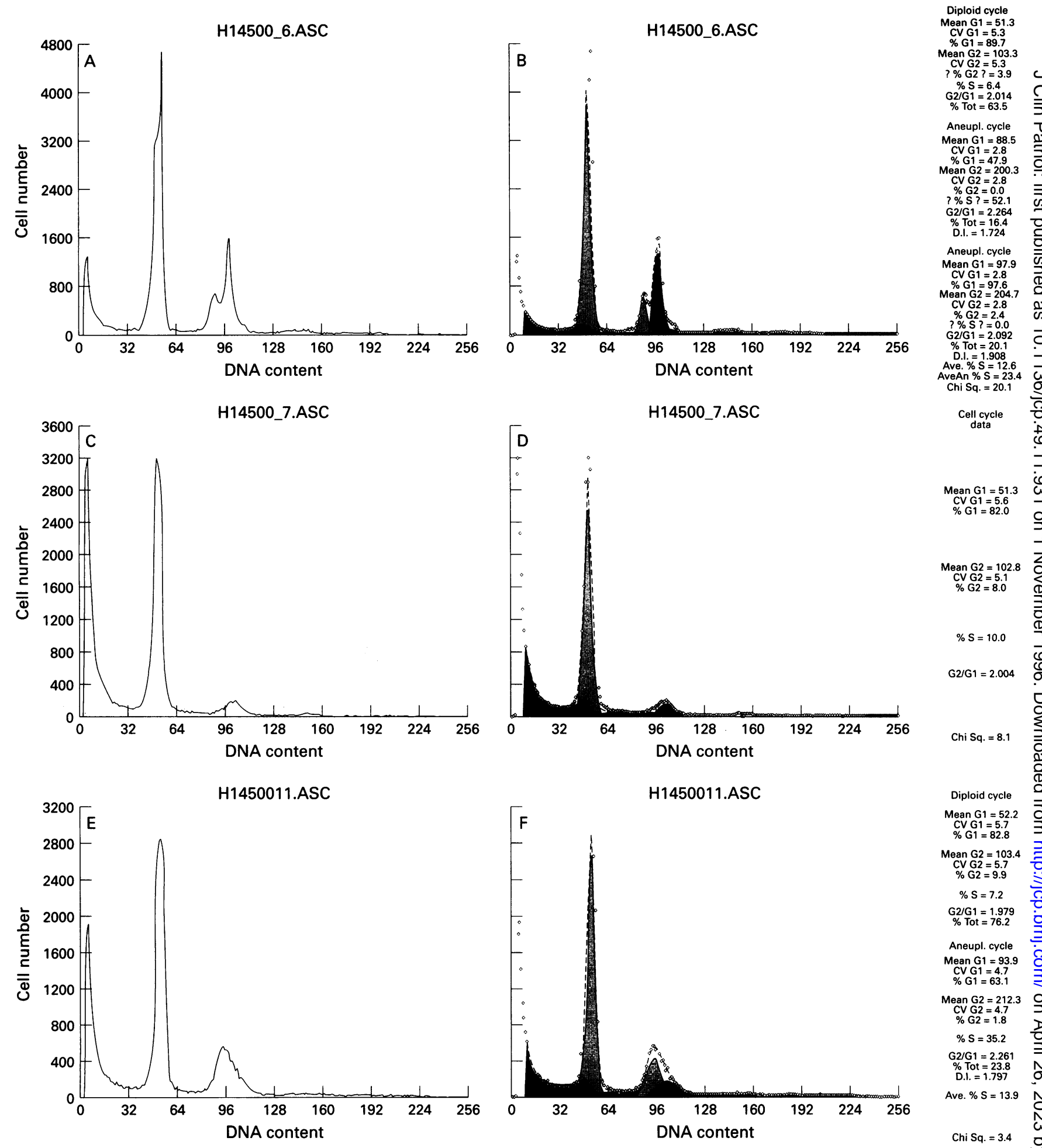

Figure 1 Example of intra-tumour heterogeneity in DNA ploidy and DNA index measurements. (A) Raw data. (B) Data from $(A)$ after interpretation. The DNA histogram is multiploid with the following $D N A$ indexes: $1.00,1.72,1.91$. The shoulder in the $G_{o} / G_{1}$ peak is ignored. (C) Raw data from another sample from the same case. (D) Data from (C) after interpretation. Only one cell cycle is present with a DNA index of 1.00. (E) Raw data from another sample from the same case. $(F)$ Data from (C) after interpretation. Two cell cycles are present with DNA indexes of 1.00 and 1.80.

ANALYSIS OF DNA HISTOGRAMS

The MultiCycle program can separate $G_{0} / G_{1}$, $S$ and $G_{2} / M$ phases of up to three cell cycles in one DNA histogram. In previous studies ${ }^{17} 18$ we have developed a protocol which produces highly reproducible intra- and inter-laboratory results. Briefly, background correction is applied with the sliced nuclei option. Zero order $S$ phase is chosen and the $G_{2} / G_{1}$ ratio is not fixed. The first peak in the DNA histogram after the debris peak is defined as the $G_{0} / G_{1}$ phase of the diploid cell cycle. If the $G_{2} / M$ phase of the diploid cell cycle contains more than $10 \%$ of the population, the histogram is re-analysed for two cell cycles, the second $\mathrm{G}_{0} / \mathrm{G}_{1}$ peak being in the tetraploid region. The first DNA index is defined, as usual, as the ratio between the channel numbers of the modes of the $G_{0} / G_{1}$ peaks of the second cell cycle and the first (diploid) cell cycle, the DNA index for a single cell cycle being 1.00. Analogously, the second DNA index is defined as the ratio between the channel numbers of the modes of the $G_{0} / G_{1}$ peaks of the third and first 
Table 4 Intra-tumour heterogeneity with regard to the DNA index of each fresh frozen sample and of the averaged DNA histogram

\begin{tabular}{|c|c|c|c|c|}
\hline Tumour & $n$ (samples) & $D N A$ index (number of cases) & $\begin{array}{l}\text { Number of } \\
\text { stemlines }\end{array}$ & $\begin{array}{l}\text { Averaged DNA } \\
\text { histogram }\end{array}$ \\
\hline 1 & 4 & $1.00(4), 1.62(1), 1.73(1), 1.74(1), 1.77(1), 1.83(1), 1.90(1)$ & 3 & $1.00,1.8$ \\
\hline 2 & 6 & $1.00(6), 1.66(1), 1.75(2), 1.76(2), 1.78(2), 1.79(1)$ & 2 & $1.00,1.7$ \\
\hline 3 & 6 & $1.00(6), 1.88(1), 1.89(1), 1.97(1), 2.11(1), 2.12(1), 2.17(1)$ & 3 & $1.00,1.9$ \\
\hline 4 & 8 & $1.00(8), 1.59(2), 1.64(1), 1.65(1), 1.67(1), 1.71(3), 1.72(1)$ & 2 & $1.00,1.7$ \\
\hline 5 & 8 & $1.00(8), 1.74(1), 1.84(1), 1.89(1), 1.91(1)$ & 3 & $1.00,1.9$ \\
\hline 6 & 9 & $1.00(9), 1.03(1), 1.76(1), 1.87(1)$ & 3 & 1.00 \\
\hline 7 & 10 & $1.00(10), 1.72(1), 1.80(1), 1.88(1), 1.91(1), 1.97(1)$ & 3 & $1.00,1.9$ \\
\hline 9 & 13 & $1.00(13), 1.05(1), 1.06(1), 1.07(1), 1.10(1)$ & 2 & 1.00 \\
\hline 10 & 14 & $1.00(14), 1.07(2), 1.09(2), 1.15(8), 1.16(2)$ & 2 & $1.00,1.2$ \\
\hline 11 & 14 & $1.00(14)$ & 1 & 1.00 \\
\hline 12 & 16 & $1.00(16), 1.46(1), 1.47$ (2), 1.51 (2), 1.54 (3), 1.55 (3), 1.56 (2), 1.57 (1), 1.58 (1), 1.59 (1), 1.60 (1) & 2 & $1.00,1.5$ \\
\hline 13 & 21 & $1.00(21), 1.05(1), 1.06(1), 1.10(1), 1.52(1), 1.65(1)$ & 3 & 1.00 \\
\hline 14 & 29 & $1.00(29), 1.09(1), 1.10(1), 1.11(1), 1.64(1), 1.72(1), 1.81(1), 1.92(1), 2.00(1), 2.02(1), 2.03(1)$ & 5 & $1.00,2.00$ \\
\hline 15 & 30 & $1.00(30)$ & 1 & 1.00 \\
\hline 16 & 34 & $1.00(34), 1.08(2), 1.44(1), 1.60(4), 1.61(2), 1.63(3), 1.64(2), 1.65(5), 1.66(2), 1.70(1), 1.75(1), 2.73(1)$ & 5 & $1.00,1.6$ \\
\hline 17 & 40 & $1.00(40), 1.05(1), 1.06(1), 1.10(1)$ & 2 & 1.00 \\
\hline
\end{tabular}

Table 5 Intra-tumour heterogeneity with regard to the DNA index of each paraffin wax embedded sample and of the averaged DNA histogram

\begin{tabular}{|c|c|c|c|c|}
\hline Tumour & $n$ (samples) & $D N A$ index (number of cases) & $\begin{array}{l}\text { Number of } \\
\text { stemlines }\end{array}$ & $\begin{array}{l}\text { Averaged DNA } \\
\text { histogram }\end{array}$ \\
\hline 1 & 3 & $1.00(3), 2.48(1), 2.43(1), 2.52(1)$ & 2 & $1.00,2.50$ \\
\hline 2 & 4 & $1.00(4), 1.29(2), 2.33(1), 2.53(1), 3.02(1), 3.14(1)$ & 4 & $1.00,1.28$ \\
\hline 3 & 6 & $1.00(6), 1.22(1), 2.38(2), 2.41(1)$ & 3 & $1.00,2.01$ \\
\hline 4 & 6 & $1.00(6), 1.57(1), 1.60(1), 1.62(1), 1.70(2), 1.71(1)$ & 2 & $1.00,1.64$ \\
\hline 5 & 6 & $1.00(6), 1.90(2), 1.91(1), 1.93(2), 1.94(1)$ & 2 & $1.00,1.92$ \\
\hline 6 & 6 & $1.00(6), 1.15(2), 1.17(1), 1.18(1)$ & 2 & $1.00,1.18$ \\
\hline 7 & 6 & $1.00(6), 1.22(1), 1.24(1), 1.26(1)$ & 2 & $1.00,1.25$ \\
\hline 9 & 6 & $1.00(6), 1.15(1)$ & 2 & 1.00 \\
\hline 10 & 8 & $1.00(8), 1.89(1), 1.92(2), 1.94(1), 1.95(2), 1.96(1), 1.97(1), 3.10(1), 3.19(1), 3.38(1)$ & 4 & $1.00,2.00$ \\
\hline 11 & 8 & $1.00(8)$ & 1 & 1.00 \\
\hline 12 & 9 & $1.00(9), 1.91(1), 1.94(1), 2.04(1), 2.28(1), 2.30(1), 2.37(1), 2.39(1), 2.43(2)$ & 3 & $1.00,2.21$ \\
\hline 13 & 9 & $1.00(9), 1.14(1), 1.16(1), 1.21(2), 1.22(2), 1.23(1), 1.25(1), 1.27(1)$ & 2 & $1.00,1.23$ \\
\hline 14 & 9 & $1.00(9), 2.11(1), 2.15(1), 2.21(1), 2.22(1), 2.30(3), 2.34(1), 2.35(1)$ & 3 & $1.00,2.24$ \\
\hline 15 & 9 & $1.00(9), 1.09(1), 1.21(2), 1.22(2), 1.26(2), 1.28(1)$ & 3 & $1.00,1.14$ \\
\hline 16 & 9 & $1.00(9)$ & 1 & 1.00 \\
\hline 17 & 10 & $1.00(10), 1.62(1), 2.45(1), 2.61(1), 2.63(1), 2.74(1), 2.99(1), 3.05(1), 3.61(1), 3.76(1), 3.89(1)$ & 7 & $1.00,3.12,3.41$ \\
\hline 18 & 11 & $1.00(11), 1.70(2), 1.71(1)$ & 2 & $1.00,1.91$ \\
\hline 20 & 12 & $1.00(12), 1.15(2), 1.17(1), 1.19(2), 1.21(1), 1.25(1), 1.26(1), 1.35(1), 1.36(1), 1.37(1), 1.52(1)$ & 4 & $1.00,1.22$ \\
\hline 21 & 12 & $1.00(12), 1.11(1), 1.13(1)$ & 2 & $1.00,1.10$ \\
\hline
\end{tabular}

cell cycles. The average $\% \mathrm{~S}$ phase fraction (total number of cells in all $S$ phases/(total number of cells - debris) $\times 100$ ) is calculated as this $S$ phase variable was found to be consistently reproducible in previous studies. ${ }^{17} 18$

DNA ploidy was classified as diploid (presence of one cell cycle) or aneuploid (presence of at least one additional cell cycle).

ASSESSMENT OF HETEROGENEITY

Intra-tumour heterogeneity with regard to DNA ploidy was defined as the presence of DNA histograms with different ploidy classifications in different samples of the same tumour.

With regard to the DNA index, some variation is induced by the measuring and interpretation process. Therefore, a DNA index interval has to be defined inside which DNA indexes are assumed to represent the same stemline. Based on the results of a study by Benson and Braylan ${ }^{22}$ on the sensitivity of detecting aneuploidy, this interval was, in the present study with an average coefficient of variation of $5 \%$, set at 0.15 , taking the sample with the lowest DNA index as the reference. A DNA index of 1.00 was always regarded as a separate stemline. In addition, for each case, the number of samples required to detect the highest DNA ploidy class (grouped as diploid versus aneuploid) with a certain probability was calculated.

Intra-tumour heterogeneity for $\% S$ phase fraction was defined as a difference from the average $\% \mathrm{~S}$ phase fraction value of more than $5 \%$ in the different DNA histograms, as suggested by Kallioniemi. ${ }^{23}$ For each tumour, the range (maximum to minimum) for the average $\% \mathrm{~S}$ phase value was calculated as another measure of $\% S$ phase variability.

STATISTICAL EVALUATION

The correlation between the number of stemlines and the $\% \mathrm{~S}$ phase range on the one hand and tumour size and grade on the other was evaluated using linear regression analysis and the $\chi^{2}$ test (Biomedical Package (BMDP), Statistical Solutions, Cork, Ireland). Cut-off values were chosen in such a way that equal groups were obtained; $p<0.05$ was considered significant.

\section{Results}

DNA PLOIDY AND DNA STEMLINES

Of the 274 fresh frozen and 167 paraffin wax embedded breast tumour samples, 59\% (161/ $274)$ and $37 \%(62 / 167)$ were classified as diploid, respectively. Intra-tumour heterogeneity with regard to DNA ploidy is shown in table 2 and was present in 53\% (nine of 17) of fresh frozen and $38 \%$ (eight of 21 ) paraffin wax embedded samples. Seven (12\%) of 58 paraffin 
Table 6 Intra-tumour heterogeneity of fresh frozen samples with regard to the ranges of the cell cycle variables and the values obtained from the averaged DNA histograms

\begin{tabular}{lcccc}
\hline Tumour & $n$ (samples) & $\%$ Diploid (averaged) & $\%$ S average (averaged) & Aneuploid average \%S (averaged) \\
\hline 1 & 4 & $36.8-66.6(43.5)$ & $9.8-16.6(9.5)$ & $16.5-49.5(16.8)$ \\
2 & 6 & $40.5-87.4(62.5)$ & $6.6-18.0(12.8)$ & $12.2-67.7(7.0)$ \\
3 & 6 & $37.6-84.2(46.8)$ & $7.6-23.3(12.4)$ & $12.0-81.6(20.2)$ \\
4 & 8 & $50.4-77.4(62.4)$ & $8.1-15.2(11.2)$ & $14.4-37.6(23.1)$ \\
5 & 8 & $65.6-94.7(86.0)$ & $4.5-10.8(9.7)$ & $13.6-72.4(35.9)$ \\
6 & 9 & $42.8-100.0(100.0)$ & $3.6-13.6(6.4)$ & $13.0-60.4(-)$ \\
7 & 11 & $63.5-100.0(79.9)$ & $6.8-13.9(15.7)$ & $23.4-35.2(43.0)$ \\
8 & 12 & $34.7-100.0(100.0)$ & $7.7-22.1(12.8)$ & $17.4-17.4(-)$ \\
9 & 13 & $20.2-100.0(100.0)$ & $6.4-19.5(10.0)$ & $1.2-29.5(-)$ \\
10 & 14 & $29.6-55.3(59.9)$ & $12.9-20.8(16.7)$ & $0.0-20.8(36.7)$ \\
11 & 14 & $100.0-100.0(100.0)$ & $3.6-9.9(5.7)$ & $-\{-)$ \\
12 & 16 & $34.0-70.6(45.0)$ & $10.7-26.9(17.9)$ & $2.4-35.5(28.6)$ \\
13 & 21 & $8.8-100.0(100.0)$ & $2.8-13.7(6.6)$ & $0.0-6.8(-)$ \\
14 & 29 & $25.0-100.0(85.4)$ & $6.1-22.0(15.8)$ & $1.7-81.0(47.5)$ \\
15 & 30 & $100.0-100.0(100.0)$ & $7.5-14.1(9.2)$ & $-(-)$ \\
16 & 34 & $33.1-100.0(88.9)$ & $9.5-31.6(21.0)$ & $13.8-98.2(70.9)$ \\
17 & 40 & $12.8-100.0(100.0)$ & $4.3-20.8(12.9)$ & $3.8-28.5(-)$ \\
\hline
\end{tabular}

Table 7 Intra-tumour heterogeneity of the paraffin wax embedded samples with regard to the ranges of the cell cycle variables and the values obtained from the averaged DNA histograms

\begin{tabular}{lllccc}
\hline Tumour & $n$ (blocks) & $n$ (samples) & \% Diploid (averaged) & \%S average (averaged) & Aneuploid average \%S (averaged) \\
\hline 1 & 1 & 3 & $31.7-43.1(38.8)$ & $16.8-20.3(21.3)$ & $26.3-29.7(34.8)$ \\
2 & 1 & 4 & $7.5-12.0(15.8)$ & $9.9-31.5(23.5)$ & $0.7-30.9(23.3)$ \\
3 & 2 & 6 & $24.0-100.0(69.4)$ & $4.6-15.8(16.4)$ & $19.8-45.3(52.2)$ \\
4 & 2 & 6 & $66.7-88.5(78.8)$ & $20.4-32.1(26.4)$ & $41.1-67.5(63.9)$ \\
5 & 2 & 6 & $40.7-49.0(50.6)$ & $18.6-24.3(22.6)$ & $28.8-36.1(36.1)$ \\
6 & 2 & 6 & $1.2-100.0(50.8)$ & $9.4-13.2(13.4)$ & $12.2-25.4(27.4)$ \\
7 & 2 & 6 & $8.3-100.0(17.0)$ & $4.4-18.5(14.8)$ & $9.3-20.5(17.9)$ \\
8 & 2 & 6 & $100.0-100.0(100.0)$ & $2.2-15.9(11.4)$ & $-(-)$ \\
9 & 2 & 6 & $46.6-100.0(100.0)$ & $2.4-24.1(23.2)$ & $22.9-22.9(-)$ \\
10 & 3 & 8 & $21.5-89.7(60.1)$ & $4.5-67.3(7.0)$ & $9.8-85.7(13.5)$ \\
11 & 3 & 8 & $100.0-100.0(100.0)$ & $5.3-21.6(12.0)$ & $-(-)$ \\
12 & 3 & 9 & $22.3-56.8(35.6)$ & $2.3-13.7(12.8)$ & $5.4-26.8(19.8)$ \\
13 & 3 & 9 & $32.8-73.0(50.5)$ & $17.4-37.3(28.1)$ & $2.6-46.1(36.5)$ \\
14 & 3 & 9 & $43.4-88.0(74.1)$ & $7.7-12.2(10.8)$ & $6.8-40.0(26.8)$ \\
15 & 3 & 9 & $8.4-100.0(21.8)$ & $1.3-17.8(25.2)$ & $0.0-1.3(24.8)$ \\
16 & 3 & 9 & $100.0-100.0(100.0)$ & $8.5-18.5(17.2)$ & $-(-)$ \\
17 & 4 & 10 & $34.4-82.7(57.3)$ & $9.8-62.0(67.8)$ & $0.0-49.2(54.7)$ \\
18 & 4 & 11 & $78.3-100.0(86.9)$ & $8.3-20.7(13.8)$ & $31.6-48.4(40.2)$ \\
19 & 4 & 12 & $1.4-100.0(53.5)$ & $13.3-34.6(21.0)$ & $0.0-62.7(30.2)$ \\
20 & 4 & 12 & $6.8-55.3(33.5)$ & $11.7-46.4(22.8)$ & $0.0-46.5(14.3)$ \\
21 & 4 & 12 & $8.9-100.0(32.8)$ & $0.0-18.3(14.1)$ & $13.2-19.1(19.1)$ \\
\hline
\end{tabular}

wax embedded blocks produced both DNA diploid and aneuploid histograms (fig 1). Table 3 shows the number of tumour samples required to detect the highest DNA ploidy class (DNA aneuploidy when intra-tumour heterogeneity was present). When six samples were measured, the highest DNA ploidy class was detected in $71 \%$ of fresh frozen and $86 \%$ of paraffin wax embedded samples. Analysis of more than six samples did not improve the results obtained. In the artificially averaged DNA histograms, DNA aneuploidy was lost in $36 \%$ (five cases) of fresh frozen and $6 \%$ (one case) of paraffin wax embedded samples.

Tables 4 and 5 show the number of stemlines detected, reflected by the first DNA index, in the different DNA histograms of each breast cancer, for the fresh frozen and paraffin wax embedded material, respectively. As our definition defines the first peak as the diploid $G_{0} / G_{1}$ peak, the DNA diploid stemline was always present. There was naturally more stemline heterogeneity than DNA ploidy heterogeneity. The average number of stemlines per case was 2.6 for both fresh frozen and paraffin wax embedded material. On the artificially averaged DNA histograms, in $65 \%$ (11 cases) of the fresh frozen and $43 \%$ (nine cases) of the paraffin wax embedded samples, at least one of the stemlines present in the individual DNA histograms was lost.
Furthermore, on pooling the fresh frozen and paraffin wax embedded data, there were no significant correlations between the number of stemlines present or between tumour size and grade.

\section{CELL CYCLE VARIABLES}

Tables 6 and 7 show the ranges of the cell cycle variables (\% diploid cells, average $\% S$ phase fraction, average \% aneuploid $S$ phase fraction) of fresh frozen and paraffin wax embedded samples, respectively. In summary, all breast cancer cases showed high intra-tumour heterogeneity for these cell cycle variables. The widest range for per cent diploid cells was found for tumour $13(8.8-100 \%)$, a fresh frozen sample, and tumour $6(1.2-100 \%)$, a paraffin wax embedded sample (fig 2).

With respect to average $\% \mathrm{~S}$ phase fraction, the fresh frozen material generally showed narrower ranges than the paraffin wax embedded material. The widest range for the fresh frozen samples was $9.5-31.6 \%$ (tumour 16) and for the paraffin wax samples was $4.5-67.3 \%$ (tumour 10). Overall, the average aneuploid $\% \mathrm{~S}$ phase value showed even wider ranges than the average \%S phase value. On pooling the fresh frozen and paraffin wax embedded data, there were no significant correlations between $\% \mathrm{~S}$ phase fraction on the one hand and 

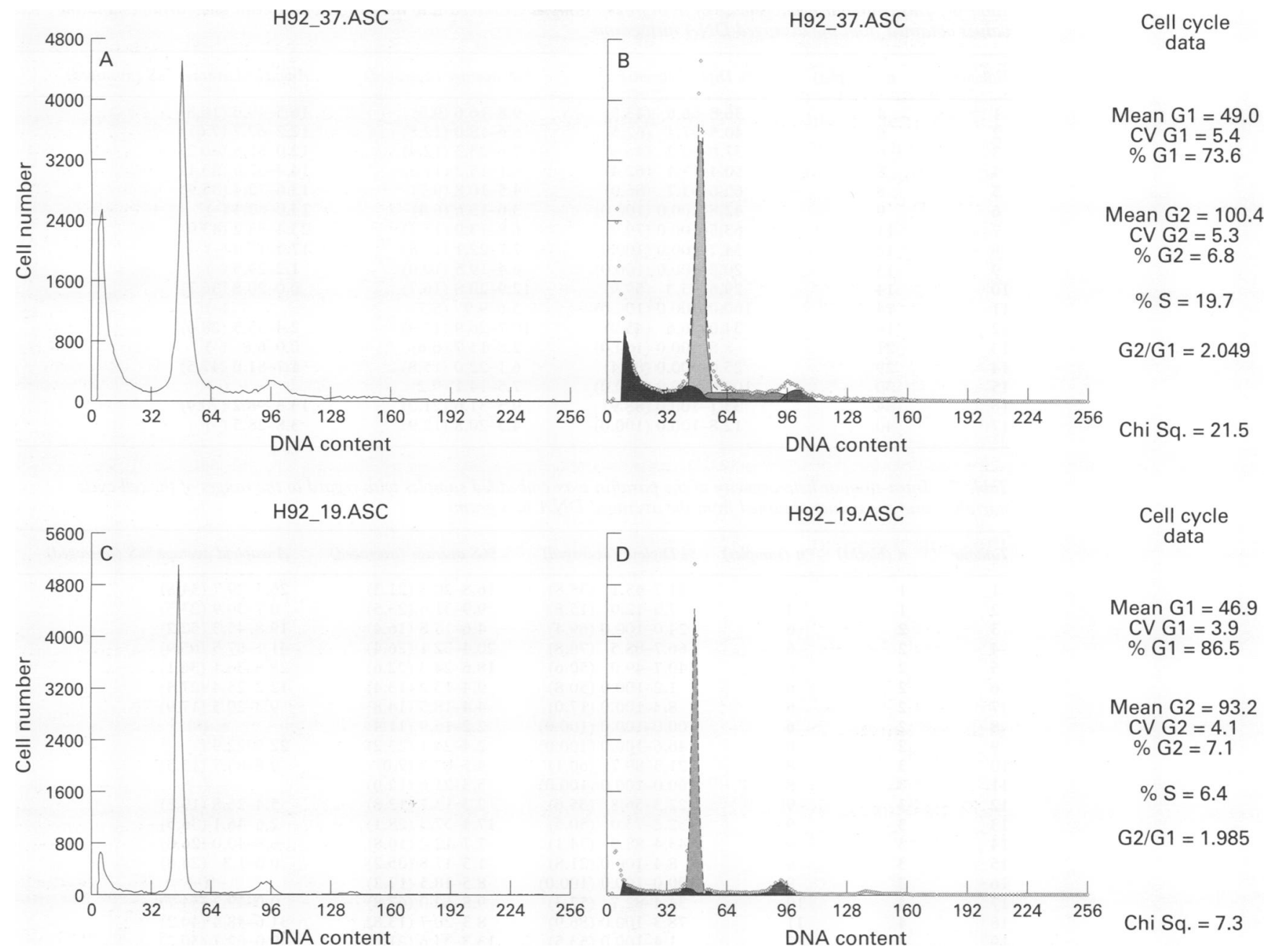

Figure 2 Example of intra-tumour heterogeneity in $\% S$ phase fraction measurements in the same tumour. (A) Raw data. (B) Data from (A) after interpretation with a $\% S$ phase fraction of $19.7 \%$. (C) Raw data from another sample from the same case. (D) Data from (C) after interpretation. The $\% S$ phase fraction is now much lower at $6.4 \%$.

tumour size and grade on the other, although there was a trend for correlation with tumour size.

\section{Discussion}

Previous studies of intra-tumour heterogeneity in breast cancer have concentrated mainly on DNA ploidy ${ }^{23-27}$ and the DNA index. ${ }^{2324} 28$ The present study showed high intra-tumour heterogeneity in breast tumours with regard to DNA ploidy and cell cycle variables measured by flow cytometry. Consequencely, at least six samples of fresh frozen or paraffin wax embedded tissue had to be measured to detect DNA aneuploidy in $71 \%$ and $86 \%$ of cases, respectively. Furthermore, these six samples should be prepared and measured separately (especially for fresh frozen material), as the computer simulation showed that the artificially averaged DNA histograms, which simulate measuring an homogenised suspension from all samples, lead to the loss of DNA aneuploidy in some cases. For cell cycle variables, especially $\% \mathrm{~S}$ phase fraction, intra-tumour heterogeneity was high for both fresh frozen and paraffin wax embedded samples. These findings may explain the conflicting prognostic results reported in the literature. Paraffin wax embedded material showed less intra-tumour heterogeneity for DNA ploidy. This cannot be explained by differences in the sizes of the tumour samples measured. Rather, these differences are probably due to the procedure used to cut slices from the paraffin wax blocks, resulting a more representative sample from the entire cut tumour surface.

The findings of the present study confirm those from previous studies. According to the definition of intra-tumour heterogeneity used in the present study, Beerman et $a^{24}$ obtained DNA diploid and aneuploid histograms in $32 \%$ of fresh frozen and paraffin wax embedded breast cancer samples. Fernö et al, ${ }^{25} \mathrm{Fuhr}$ et $a l^{26}$ and Prey et $a l^{27}$ studying intra-tumour heterogeneity in fresh frozen tissue, found discrepancies in $23 \%, 19 \%$ and $25 \%$, respectively, of cases. With regard to the DNA index, Bonsing $e t a l^{8}$ found intra-tumour heterogeneity in $64 \%$ of cases. Kallioniemi ${ }^{23}$ found $13 \%$ intratumour heterogeneity when he measured the DNA index in paraffin wax embedded breast cancer tissue.

In the present study, no significant correlations were found between the number of stemlines and intra-tumour variability of $\% S$ phase fraction on the one hand and tumour size and grade on the other, indicating that heterogeneity may also be present in small tumours.

Overall, intra-tumour heterogeneity for DNA ploidy, DNA index and $\% S$ phase 
fraction found in the present study is somewhat higher than in other studies. This may have been because of the greater number of samples analysed in the present study. It is unlikely that the difference is due to the size of the tumour samples as these were within the usual range. However, not all studies give details of the sizes of the fresh tumour material studied. We also used a different method of cell cycle analysis. Kallioniemi ${ }^{23}$ used Coulter Software and the method described by Baisch et $a l^{29}$ whereas Fernö et $a l^{25}$ used planimetry to calculate the $\% \mathrm{~S}$ phase fraction. It is not clear whether these methods are as reliable as that used in the present study. ${ }^{17} 18$

The clinical consequences of analysing multiple samples for $\% S$ phase fraction are not clear as yet. Prospective studies are required to determine whether the highest $\% S$ phase fraction value or the average value is more useful in the clinical context.

In conclusion, high intra-tumour heterogeneity for breast cancer was found for DNA ploidy, the DNA index and \%S phase fraction measured by flow cytometry, which may explain the conflicting prognostic results reported in the literature. To detect aneuploid cells, six samples may have to be prepared and measured separately. Measurement of these variables may be more reliable in paraffin wax sections because the thick slices provide a more representative sample.

We thank Dr Hans $S$ de Jong for his assistance in preparing the paraffin wax material. This work was supported by grant 28-1814 from the Praeventiefonds.

1 Beerman $\mathrm{H}$, Kluin $\mathrm{PhM}$, Hermans J, van de Velde $\mathrm{CJH}$, Cornelisse CJ. Prognostic significance of DNA-ploidy in a series of 690 primary breast cancer patients. Int $\mathcal{f}$ Cancer 1990;45:34-9.

2 Bosari S, Lee AKC, Tahan SR, Figoni MAT, Wiley BD, Heatley GJ, et al. DNA flow cytometric analysis and prognosis of axillary lymph node-negative breast carcinoma. Cancer 1992;70:1943-50.

3 Clark GM, Dressler LG, Owens MA, Pounds G, Oldakker T, McGuire WL. Prediction of relapse or survival in patients with node-negative breast cancer by DNA flow cytometry. N Engl F Med 1989;320:627-33.

4 Cornelisse CJ, Velde van de CJH, Caspers RJC, Moolenaar AJ, Hermans J. DNA ploidy and survival in breast cancer AJ, Hermans J. DNA ploidy and survients. Cytometry 1987;8:225-34.

patients. Cytometry 1987;8:225-34.
5 Fisher B, Gunduz N, Costantino J, Fisher ER, Redmond C, Mamounas EP, et al. DNA flow cytometric analysis of primary operable breast cancer. Cancer 1991;68:1465-75.

6 Friedlander ML, Hedley DW, Taylor IW. Clinical and biological significance of aneuploidy in human tumours. $f$ Clin Pathol 1984;37:961-74.

7 Joensuu H, Toikkanen S, Klemi PJ. DNA index and S-phase fraction and their combination as prognostic factors in operabel ductal breast carcinoma. Cancer 1990;66:331-49.

8 Kallioniemi OP, Hietanen $T$, Mattila J, Lehtinen M, Lauslahti K, Koivula T. Aneuploid DNA content and high $\mathrm{S}$-phase fraction of tumour cells are related to poor prognosis in patients with primary breast cancer. Eur f Cancer Clin Oncol 1987;23:277-82

9 Kallioniemi OP, Blanco G, Alavaikko M, Hietanen T, Mattila J, Lauslahti $\mathrm{K}$. Tumour DNA ploidy as an independen prognostic factor in breast cancer. $B r f$ Cancer 1987;56: $637-42$.

10 Kallioniemi OP, Blanco G, Alavaikko $M$, Hietanen T, Matilla J, Lauslahti $\mathrm{K}$, et al. Improving the prognostic value of DNA flow cytometry in breast cancer by combining DNA DNA flow cytometry in breast cancer by combining D
index and S-phase fraction. Cancer 1988;62:2183-90.

11 Uyterlinde AM, Baak JPA, Schipper NW, Peterse H, Matze $\mathrm{E}, \mathrm{Meijer} \mathrm{CJL}$. Further evaluation of the prognostic value of morphometric and flow cytometric parameters in breas cancer patients with long follow-up. Int $\mathcal{F}$ Cancer 1990;45: 1-7.

12 Baildam AD, Zaloudik J, Howell A, Barnes DM, Turnbull $\mathrm{L}$, Swindell R, et al. DNA analysis by flow cytometry, response to endocrine treatment and prognosis in advanced carcinoma of the breast. Br f Cancer 1987;55:553-9

13 Keyhani-Rofagha S, O'Toole RV, Farrar WB, SickleSantanello B, DeCenzo J, Young D. Is DNA ploidy an independent prognostic indicator in infiltrative nodenegative breast adenocarcinoma? Cancer 1990;65:1577-82.

14 Muss HB, Kute TE, Smith LR, Booher C, Long R, Kammire $\mathrm{L}$, et al. The relation of flow cytometry to clinical and biologic characteristics in women with node negative primary breast cancer. Cancer 1989;64:1894-900.

15 Owainati AAR, Robins RA, Hinton C, Ellis IO, Dowle CS Ferry B, et al. Tumour aneuploidy, prognostic parameters and survival in primary breast cancer. Br $\mathcal{F}$ Cancer $1987 ; 55$; 449-54.

16 O'Reilly SM, Camplejohn RS, Barnes DM, Millis RR, Allen $\mathrm{D}$, Rubens $\mathrm{RD}$, et al. DNA index, S-phase fraction, histological grade and prognosis in breast cancer. $\mathrm{Br} f \mathrm{Can}$ cer 1990;61:671-74.

17 Bergers E, Diest PJ van, Baak JPA. Reproducibility of semiautomated cell cycle analysis of flow cytometric DNAhistograms of fresh breast cancer material. Anal Cell Patho 1995;8:1-13.

18 Bergers E, Montironi R, Diest van PJ, Prete E, Baak JPA Inter-laboratory reproducibility of semi-automated cell cycle analysis of flow cytometric DNA-histograms obtained from fresh material of 1295 breast cancer cases. Hum Pathol 1996;27:553-60.

19 Ellis IO, Galea M, Broughton N, Locker A, Blamey RW, Elston CW. Pathological prognostic factors in breas cancer: II. Histological type. Relationship with survival in a large study with long term follow up. Histopathology 1992;20:479-89.

20 Vindelov LL, Christensen IJ, Nissen NI. A detergenttrypsin method for the preparation of nuclei for flow cytometric DNA analysis. Cytometry 1983;3:322-7.

21 Hedley DW, Friedlander ML, Taylor IW, Rugg CA, Musgrove EA. Method for analysis of cellular DNA content of paraffin-embedded pathological material using flow cytometry. $\mathcal{F}$ Histochem Cytochem 1983;31:1333-5.

22 Benson NA, Braylan RC. Evaluation of sensitivity in DNA aneuploidy detection using a mathematical model. Cytometry 1994;15:53-8.

23 Kallioniemi OP. Comparison of fresh and paraffinembedded tissue as starting material for DNA flow cytometric and evaluation of intratumour heterogeneity. Cytometry 1988;9:164-9.

24 Beerman H, Smit VTHBM, Kluin PM, Bonsing BA Hermans J, Cornelisse CJ. Flow cytometric analysis of DNA stemline heterogeneity in primary and metastatic breast cancer. Cytometry 1991;12:147-54.

25 Fernö M, Baldetorp B, Ewers SB, Idvall I, Olsson $H$ Siggurdson $\mathrm{H}$, et al. One or multiple samplings for flow cytometric DNA analyses in breast cancer-Prognostic implications? Cytometry 1992;13:241-9.

26 Fuhr JE, Frye A, Kattine AA, van Meter S. Flow cytometric determination of breast tumour heterogeneity. Cancer 1990;67:1401-5.

27 Prey MU, Meyer JS, Stone KR, McDivitt RW. Heterogeneity of breast carcinomas determined by flow cytometric analysis. F Surg Oncol 1985;29:35-9.

28 Bonsing BA, Beerman H, Kuipers-Dijkhoorn N, Fleuren GJ, Cornelisse CJ. High levels of DNA index heterogeneity in advanced breast carcinomas. Cancer 1993;71:382-91.

29 Baisch H, Göhde W, Linden WA. Analysis of PCP-data to determine the fraction of cells in the various phases of the cell cycle. Radiat Environ Biophys 1975;12:31-9. 